\title{
BMJ Open Protocol for a national blood transfusion data warehouse from donor to recipient
}

\author{
Loan $\mathrm{R}$ van Hoeven, ${ }^{1,2}$ Babette $\mathrm{H}$ Hooftman, ${ }^{3}$ Mart $\mathrm{P}$ Janssen, ${ }^{1,2}$ \\ Martine C de Bruijne, ${ }^{3}$ Karen M K de Vooght, ${ }^{4}$ Peter Kemper, ${ }^{1}$ \\ Maria M W Koopman ${ }^{5}$
}

To cite: van Hoeven LR, Hooftman BH, Janssen MP, et al. Protocol for a national blood transfusion data warehouse from donor to recipient. BMJ Open 2016;6: e010962. doi:10.1136/ bmjopen-2015-010962

- Prepublication history for this paper is available online. To view these files please visit the journal online (http://dx.doi.org/10.1136/ bmjopen-2015-010962).

$\mathrm{LRvH}$ and BHH contributed equally.

Received 23 December 2015 Revised 10 June 2016 Accepted 17 June 2016

\section{CrossMark}

For numbered affiliations see end of article.

Correspondence to Loan $\mathrm{R}$ van Hoeven; L.R.vanHoeven-3@ umcutrecht.nl

\section{ABSTRACT}

Introduction: Blood transfusion has health-related, economical and safety implications. In order to optimise the transfusion chain, comprehensive research data are needed. The Dutch Transfusion Data warehouse (DTD) project aims to establish a data warehouse where data from donors and transfusion recipients are linked. This paper describes the design of the data warehouse, challenges and illustrative applications.

Study design and methods: Quantitative data on blood donors (eg, age, blood group, antibodies) and products (type of product, processing, storage time) are obtained from the national blood bank. These are linked to data on the transfusion recipients (eg, transfusions administered, patient diagnosis, surgical procedures, laboratory parameters), which are extracted from hospital electronic health records. Applications: Expected scientific contributions are illustrated for 4 applications: determine risk factors, predict blood use, benchmark blood use and optimise process efficiency. For each application, examples of research questions are given and analyses planned.

Conclusions: The DTD project aims to build a national, continuously updated transfusion data warehouse. These data have a wide range of applications, on the donor/production side, recipient studies on blood usage and benchmarking and donor-recipient studies, which ultimately can contribute to the efficiency and safety of blood transfusion.

\section{INTRODUCTION}

In 1874, a first review, or 'short resume', was published about the current evidence regarding blood transfusions, concluding that transfusion might be 'an effective mean of saving life when all other means fail', yet this subject needed more investigation. ${ }^{1}$ To date, it is widely accepted that blood transfusions can be lifesaving and can be used for the treatment of various diseases. However, since
Strengths and limitations of this study

- First Dutch Transfusion Data warehouse structure that is updated continuously.

- Covers the complete blood transfusion chain from donor to recipient.

- Can be used for answering a wide range of research questions.

- Not all Dutch hospitals are included yet, but the number is growing.

- Hospital diagnoses and procedures included might be suboptimal as the registration systems are primarily installed for the reimbursement of medical expenses.

blood transfusions may also have serious side effects, ${ }^{2}$ there is still much debate on optimal transfusion triggers. ${ }^{3}$ There is growing but inconclusive evidence that a restrictive transfusion policy is more beneficial for patients than a more liberal policy ${ }^{5}$ (exceptions might be patients with cardiac disease or oncological surgery ${ }^{6}$ ). The large variation that exists in the use of blood products between countries, between hospitals and even within hospitals ${ }^{7-10}$ indicates that-at least in part of the patients-transfusion practice is not optimal yet and that there is uncertainty about the optimal transfusion policy. Importantly, transfusion policy concerns not only the timing and quantity of the transfusions, but also other characteristics of the blood product, the donor and the production process that might affect patient outcomes. In order to investigate the magnitude and nature of the observed differences as well as gain proficient understanding of the efficiency and safety of the donor-product-recipient relationship, more data are needed.

Even though several individual hospitals and blood banks analyse data on donors and transfusion recipients, ${ }^{11}{ }^{12}$ worldwide 
initiatives that permanently monitor transfusions on a large scale are sparse. The SCANDAT database from Sweden and Denmark, originally established in 2002, now covers all donor and transfusion data nationwide since 1968 (Sweden) and 1980 (Denmark). It includes 47 years follow-up data on health outcomes regarding hospital care, cancer and death. ${ }^{13} 14$ The Recipient Epidemiology and Donor Evaluation Study (REDS-III) programme in the USA is currently preparing a similar blood donor and transfusion recipient database. ${ }^{15}$ Finland established a recipient database starting in 2002, covering in the year $200770 \%$ of all blood units delivered for all potentially transfused patients. ${ }^{16}$ Recently a Canadian donor-recipient study was initiated, containing data from hospitals in a specific region. ${ }^{17}$ In the Netherlands, the PROTON database was created to identify PROfiles of TransfusiON recipients, with data on transfusion recipients in terms of age, sex, main diagnoses and operations, number of products per hospitalisation. ${ }^{18}$

These initiatives resulted in studies on the epidemiology of the donors and recipients, providing evidence on the effect of donation and of transfusion, as well as the link between the donor and recipient. Examples of this are studies to investigate mortality risk in transfusion recipients, ${ }^{19}$ and the length of hospital stay after receiving red blood cell (RBC).$^{20}$ In the donor-recipient continuum, research topics include the risk of cancer in recipients who received a blood transfusion from donors with subclinical cancer, ${ }^{21}{ }^{22}$ the effect of the match of donor and recipient sex on survival after plasma transfusion, ${ }^{23-25}$ safety of ABO-compatible non-identical plasma versus identical plasma, ${ }^{26}$ and the effect of storage duration on recipient survival. ${ }^{27}$ Nowadays, there is a tendency to modify risk-adverse guidelines for donor selection into more liberal guidelines based on new evidence. ${ }^{29}$ Although the evidence is yet scarce, ${ }^{30}$ there are successful examples, such as extending the upper age limit for donors without increasing the number of adverse events in patients. ${ }^{31} 32$

Other results of transfusion data warehouse initiatives include the development of a model to predict the impact of demographic changes on the demand of RBCs. ${ }^{33}$ Such a model may guide donor recruitment requirements. Moreover, benchmarking events have been organised, for example, in Finland for different transfusion practices such as orthopaedics, gynaecology, haematology and heart surgery. Benchmarking discussions have led to the adoption of best practices in several cases, reflected in the reduction of differences in blood use. ${ }^{34}$

The Dutch PROTON database included hospital transfusion data starting in the year $1996 .{ }^{17}$ Unfortunately, data collection stopped after 2006. Also the database contained information on transfusion recipients, but not on the corresponding blood donors. In an effort to continue this database and expand its scope, the Dutch Transfusion Data warehouse (DTD) project started. In this project a data warehouse is developed that is intended for continuous storage, management and monitoring of transfusion data, linking the donor to the recipient. This means that the DTD facilitates research on blood usage in hospitals; it also offers the unique opportunity to study donor and product risk factors for recipient outcomes and examine efficiency over the complete transfusion chain. Thereby the creation of the DTD infrastructure will allow for comprehensive studies on blood transfusion in the Netherlands. The four main applications of this data warehouse are:

1. Determine risk factors,

2. Predict future blood products needed,

3. Benchmark blood use and

4. Improve process efficiency.

To illustrate how the DTD initiative will be used for these applications, we propose four example studies. The successful completion of this cohort will contribute to the safety of transfusion practices, and provide insights that can improve efficiency in the complete blood transfusion chain.

\section{STUDY DESIGN AND METHODS}

\section{Data collection and data set}

The data warehouse can be seen as an observational research registry, in which routinely registered administrative data are collected continuously. The starting point was the previously conducted PROTON study, ${ }^{18}$ consisting of a single collection of blood transfusion data in the Netherlands from 1996 to 2006. This data set is further extended with additional recipient, donor and product data.

In the Netherlands the blood supply is organised at a national level by Sanquin which is the sole supplier, enabling a centralised extraction of data on donors and blood products. Sanquin provides data on donor demographics, blood groups and laboratory parameters, and blood product characteristics such as product type and expiration date (table 1). In this paper, the term blood bank refers to the national blood supplier. The participating hospitals provide data related to transfusion recipients from their electronic health records (EHRs), including patient characteristics, hospitalisations, diagnoses, procedures, blood products received, blood groups, laboratory parameters and transfusion reactions (table 2). In addition, each hospital is requested to provide aggregated information on the total number of patients per indication (including non-transfused patients), allowing computation of transfusion rates. Linkage of donor and transfusion recipient data is based on the uniquely identifying combination of donation identification code and the internationally used International Society of Blood Transfusion (ISBT) product code. ${ }^{35}$ All Dutch hospitals $(n=91)$ are allowed to participate in the project; however, in order to meet the research objectives, a minimum sample of 15 academic and general Dutch hospitals in total is aimed for. Data collection started 
Table 1 Overview of donor and blood product data collected in the blood bank

\begin{tabular}{|c|c|}
\hline \multicolumn{2}{|l|}{ Donor } \\
\hline Donor number & Donor identification number \\
\hline Date of birth & Date of birth \\
\hline Gender & Gender \\
\hline ABO blood group & ABO blood group \\
\hline RhD blood group & RhD blood group \\
\hline Kell blood group & Kell blood group \\
\hline Donor entry date & Date of registration at the blood bank \\
\hline Date of first donation & Date of first donation since 2007 \\
\hline Weight & Donor weight \\
\hline Height & Donor height \\
\hline Number of donations & Total number of donations since 2007 \\
\hline $\begin{array}{l}\text { Number whole blood } \\
\text { donations }\end{array}$ & Total number of whole blood donations since 2007 \\
\hline Number plasma donations & Total number of plasma donations since 2007 \\
\hline Other donations & Total number of other donations since 2007 \\
\hline Stopping code & Stopping code \\
\hline Stopping reason & Reason to quit as a donor \\
\hline \multicolumn{2}{|l|}{ Donation } \\
\hline Donation date & Date of donation \\
\hline DIN & Donation identification number (unique for each donation) \\
\hline Donation type & Type of donation (whole blood/plasmapheresis/erythrocytapheresis/plateletpheresis) \\
\hline Donation volume & Volume of the donation (in $\mathrm{mL}$ ) \\
\hline Haemoglobin level & Haemoglobin level (in mmol/L) \\
\hline Platelet count & Number of platelets $\left(\times 10^{9} / \mathrm{L}\right)$ \\
\hline Donation location & Blood centre location \\
\hline Donation duration & Duration of donating \\
\hline Apheresis machine & Model of the machine used for apheresis \\
\hline Blood pressure & Donor blood pressure \\
\hline \multicolumn{2}{|l|}{ Product } \\
\hline Product code & $\begin{array}{l}\text { Product code (specifying product type, location of the blood bank, split product or not; } \\
\text { according to ISBT } 28 \text { Standard Specification) }\end{array}$ \\
\hline Product modifiers & Optional attribute of a product (eg, cytomegalovirus (CMV) negative/positive) \\
\hline Pool DIN & Product identification code; applies only to pooled products (thrombocytes) \\
\hline Expiration date & Date on which the product expires \\
\hline Erythrocyte antibodies & Erythrocyte antibodies in donor blood \\
\hline Platelet phenotype & Human platelet antigen (HPA) phenotype \\
\hline Date of pooling & Date of pooling; applies only to pooled products (thrombocytes) \\
\hline \multicolumn{2}{|l|}{ Transport } \\
\hline Transport date & Date of transport of the blood product \\
\hline Institute & Destination of the blood product \\
\hline Return date & Date of return of the blood product; only in case a blood product is sent back \\
\hline Return code & Return code specifying the reason for returning the blood product \\
\hline
\end{tabular}

from 2010 and will include future transfusions as well. The current number of donors in our database is $\sim 500000$, with 3500000 products issued by the blood bank covering the years 2010-2015 (this is a complete set for national coverage). These products are linked to recipient data from the participating hospitals. Based on the inclusion of 15 hospitals, we now estimate that the number of recipients in our data warehouse for the years 2010-2015 (including academic, teaching and general hospitals) will be 150000 , with $\sim 1100000$ transfusions.

Future fusions of hospitals and shifts in type and complexity of care especially in academic hospitals will be monitored closely, as these factors directly affect blood use.

\section{Data quality}

Extracting and combining large amounts of data from hospital and blood bank electronic systems is challenging: often the data have to be split into different tables (eg, by year, department or aggregation level), which afterwards have to be linked. In this process, errors can occur in the data; therefore validation of the data is very important. This starts with a uniform format and filters; we will ask the participating centres to deliver the data in the same format for every update of the data.

In order to check and improve data quality, the data warehouse will be validated on the following aspects: completeness, uniqueness, time patterns, uniformity and plausibility. Also, external concordance of the number of blood products issued by the blood bank 
Table 2 Overview of the data collected in the participating hospitals

\begin{tabular}{|c|c|}
\hline \multicolumn{2}{|l|}{ Patient } \\
\hline Patient number & Encrypted patient identification number as used by the hospital \\
\hline Date of birth & Patient's date of birth \\
\hline Gender & Patient gender \\
\hline \multicolumn{2}{|l|}{ Hospitalisation } \\
\hline Hospital & Hospital name or code \\
\hline Hospitalisation dates & Date and time of start and end of hospitalisation during which a transfu \\
\hline \multicolumn{2}{|l|}{ Diagnosis } \\
\hline Diagnoses & All diagnoses* \\
\hline Hospital discharge status & Patient status when discharged from hospital (home/dead/institution) \\
\hline \multicolumn{2}{|r|}{ 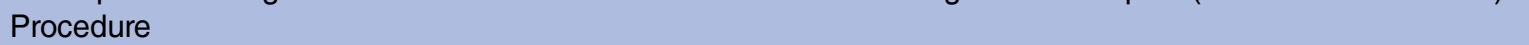 } \\
\hline Procedures & All procedures and procedure dates* \\
\hline \multicolumn{2}{|l|}{ Transfusion } \\
\hline Transfusion administration & Date and time of transfusion \\
\hline DIN & Donation identification number of the transfused unit \\
\hline Product code & Product code of the transfused unit (ISBT 128 Standard Specification) \\
\hline \multicolumn{2}{|l|}{ Blood values } \\
\hline $\mathrm{Hb}$ & Patient haemoglobin level† \\
\hline Platelet count & Patient platelet count $†$ \\
\hline Het & Patient haematocrit level† \\
\hline PT & Patient prothrombin time† \\
\hline PTT & Patient partial thromboplastin time $†$ \\
\hline Blood group & Patient $\mathrm{ABO}$ blood group \\
\hline $\mathrm{RhD}$ & Patient RhD \\
\hline Irregular antibodies & Patient irregular antibodies $†$ \\
\hline Troponin & Patient troponin level† \\
\hline \multicolumn{2}{|l|}{ Transfusion reactions } \\
\hline Transfusion reaction type & Type of transfusion reaction \\
\hline Date & Date of transfusion reaction \\
\hline Severity & Severity of transfusion reaction \\
\hline Imputability & Likelihood that the transfusion reaction is caused by the transfusion \\
\hline
\end{tabular}

${ }^{*}$ Diagnoses and procedures can be linked to hospitalisation post hoc, or to outpatient transfusions within a time interval around the transfusion. In the Netherlands, instead of diagnosis date, a start date and end date of the 'diagnosis treatment combination' trajectory are registered.

†All laboratory parameters measured during hospitalisation, or in case of outpatient transfusion all laboratory parameters within 72 hours before and after transfusion. All laboratory measurements include time stamps.

and the products transfused by the hospitals is assessed as a validity check. In the Netherlands, the blood bank registers donor and product data in one system. In contrast, some of the hospital data such as diagnoses and clinical procedures are registered in more heterogeneous ways across hospitals and sometimes even across departments within a single hospital. This means that more time is needed to validate and harmonise the hospital data. Moreover, as every registration system is subject to updates and changes, each time new data are sent to the data warehouse, the additional content will have to be validated. We intend to publish the outcomes of the validation check or at least make them available for other researchers who use the data warehouse.

\section{Indication for transfusion}

In order to facilitate the attribution of the main diagnosis (ie, indication) for a transfusion, an automated algorithm will be developed for the DTD. This algorithm will determine the most likely indication for transfusion in the case of multiple diagnoses and/or procedures per transfusion event. The algorithm will be developed based on expert opinion regarding the prioritisation of diagnoses, and will be externally validated by transfusion experts.

\section{Security, ethical and privacy aspects}

The data warehouse is hosted by the data management department of a university medical centre, in a technical environment that meets ISO-9001:2008 quality requirements. DTD has been approved by a hospital medical ethical committee and meets the requirements of Dutch privacy laws. Donors are asked for permission with a donor questionnaire before each donation. Patients are not actively asked for permission but they can opt out for use of their medical data for research purposes. Donor and patient data are transferred and stored in a de-identified format. The encryption is carried out by the contact person of the hospital, and the key to reverse encryption is stored exclusively in the hospital. In addition, non-traceability of blood donors and recipients is maximised by excluding privacy sensitive information such as name and postal code. 


\section{Organisation structure}

The DTD project team, consisting of experienced researchers in the areas of transfusion medicine, data modelling and healthcare research, is responsible for the management of the data warehouse. An advisory board, consisting of representatives of all involved disciplines, is established to handle all data requests. The main objective of the board is to guarantee the interests of all participating parties are secured. Every data provider has one contact person who, for instance, arranges the formal permission for data exchange. Researchers planning a project can gain access to the data warehouse by completing a data request form. The advisory board will determine whether the request is granted, thereby guaranteeing the interests of all parties involved.

\section{Framework blood supply chain}

The framework as presented in figure 1 provides an overview of the different steps in the transfusion chain and can be used to systematically identify and highlight areas with room for improvement. The four main applications (see Introduction section) are linked to these steps, showing which data are necessary for each application. The main contribution of the data warehouse is to allow insight into the association between blood donor characteristics and clinical outcomes (left broad arrow) and in the link between transfusion triggers and clinical outcomes (right broad arrow).

\section{APPLICATIONS}

The DTD data warehouse will be available for a wide range of purposes. To illustrate expected scientific contributions, we describe exemplary studies that could be conducted with the DTD data set.

\section{Application 1: risk factors}

Example research question: What is the effect of donor characteristics and season on the risk of (febrile) nonhaemolytic transfusion reactions (FNHTR) experienced by recipients?

Non-haemolytic transfusion reactions are relatively common, especially among haematology patients, with median reported rates for FNHTR of $4.6 \%$ for platelets and $0.33 \%$ for RBCs. ${ }^{36}$ This type of transfusion reaction seems to occur in particular with platelet transfusions but also with erythrocytes. With our data, we can determine the association of (febrile) non-haemolytic reactions with season and with certain donor characteristics (age, sex, blood group, donation frequency). Donation frequency, for example, is hypothesised to affect iron storage, and might also affect patient outcomes. The primary outcome is the risk of non-haemolytic transfusion reactions. Secondary outcomes are: risk of infections, other transfusion reactions, survival and duration of hospitalisation.

\section{Application 2: predict future blood products needed}

Example research question: What is the expected use of blood (medical vs surgical) in the Netherlands for the upcoming years?

Long-term data from 2010 up to the present will be examined for trends in blood use per product type. This information can be used to generate prognoses on the number of blood products needed in the future. Increasingly refined and specific predictions can be

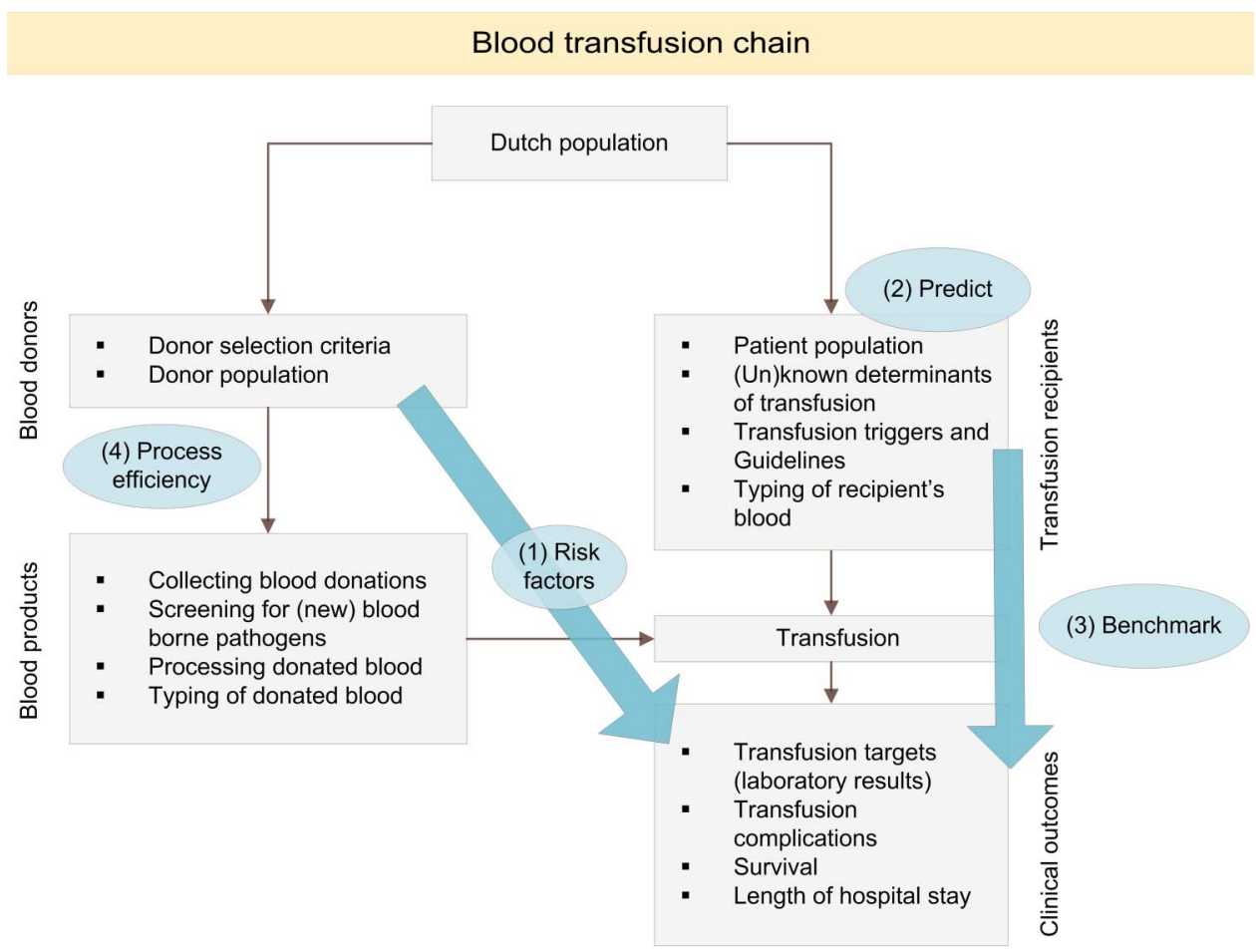

Figure 1 Framework of the blood transfusion chain. Each part of the chain can be linked to one of the four applications. 
made by distinguishing between surgical and medical use of RBCs, as well as academic, teaching and general hospitals. Observed trends in the past will be extrapolated using a regression model. Furthermore, corrections for growth and ageing of the general population can be incorporated into the predictions of the amount of blood products required.

\section{Application 3: benchmark blood use}

Example research question: What is the variation in blood use between hospitals, corrected for important determinants of blood use?

Differences in blood use between hospitals might be caused by different uses of transfusion $(\mathrm{Hb})$ triggers and targets. A benchmark study could compare these triggers between hospitals in specified patient groups, while correcting for other determinants of blood use available in the data warehouse, such as: age, sex, comorbidity burden, recent myocardial infarction, emergency or elective presentation, medical or surgical admission, diagnosis, type of surgical procedure, hospital department, preoperative haematocrit and preoperative or admission haemoglobin. ${ }^{9} 10{ }^{37}$ A multilevel random-effects model can be specified with the following levels: hospital type, hospital and patient. This allows the estimation of the variation in blood use between hospitals compared with the variation within hospitals, while controlling appropriately for differences in patient characteristics.

\section{Application 4: improve process efficiency}

Example research question: Is more extensive blood group matching between donor and recipient possible given the current donor population and is it cost-effective?

More extensive matching of donor and recipient blood groups (especially for ethnic minorities) would reduce the formation of red cell antibodies and ultimately the risk of transfusion reactions. Data on donors and patients (which reflect the availability and consumption of blood and blood types) is used to obtain insight into the logistical requirements and limitations, costs and (health) effects of various preventive matching schemes. In the ongoing BloodMatch study, ${ }^{38}$ several scenarios for matching strategies will be evaluated. These scenarios vary in the extent of blood type matching between donor and recipient for specific patient groups, and its anticipated impact on transfusion complications, the size and composition of the RBC stocks in the blood bank and hospitals, as well as the requirements for typing of the donor base in order to fulfil the demand for typed RBCs. The findings will allow balancing various aspects of the blood transfusion chain and therefore provide the means for a global optimisation of matching strategies.

\section{DISCUSSION}

Importance

The DTD project aims to build a national, up-to-date transfusion data warehouse, linking donor to recipient.
By gaining more insight into donor-related and productrelated risk factors for recipient outcomes, blood transfusions can be more tailored (minimising risks) and unnecessary transfusions avoided, further reducing transfusions reactions in patients. Especially today, facing increasing societal pressure for transparency in quality of care, multiple parties may benefit from a continuous feedback structure. For the blood bank, DTD creates the possibility to enhance the safety of transfusion on the donor and product side, as well as stock management (optimise the availability and minimise wastage of blood products). For healthcare institutions, DTD enables insight into efficient and safe use of blood products. Moreover, by participating in the project, hospitals can have better control on the way they are held accountable for blood use by external parties such as insurers and regulators. For researchers from or in collaboration with participating institutions, DTD offers access to essential data as well as a network within the clinical field. Finally, patients benefit from optimal and evidence-based quality of care in transfusion medicine.

\section{Applications and future directions}

The data warehouse will be available to different types of users, including the blood bank, hospital management, doctors and researchers. In hospitals, blood reduction policies can be directly linked to trends in blood use ${ }^{39-41}$ and new transfusion guidelines and quality indicators can be evaluated. Moreover, the availability of laboratory data can shed light on the impact and relevance of clinical and laboratory parameters (like haemoglobin level) that are used as transfusion triggers and targets. An important step in the overall process is to report (benchmark) results back to the caregivers. ${ }^{39}$ Whereas the level of detail in the indicators themselves is of less importance (especially in complex practices such as heart surgery and haematology), the discussion between clinical experts might provide novel insights, solutions to existing problems and evolvement of best practices.

The data warehouse also enables comparison of transfusion practices internationally. A great advantage is that with the presence of various patient and hospitalisation characteristics, the outcome can be adjusted for factors like age, sex, diagnosis and surgery. The scope of variables collected in DTD is similar to the SCANDAT2 database, which also focuses on donors' health using donor hospital information and already has national coverage. In future it will be possible to expand the data warehouse with additional variables, either permanently or temporarily, such as recipient survival. Additional data on vital signs (pulse, temperature and blood pressure) and laboratory parameters can also be included post hoc, depending on the specific research. Moreover, we aim to add data from patients who did not receive a blood transfusion at all, in order to calculate transfusion rates and to compare profiles of transfused recipients to non-transfused recipients. 


\section{Barriers and facilitators}

The advantage of the project's wide organisational structure is that the collaboration of hospitals, clinicians and researchers is facilitating multisite and multidisciplinary research. Moreover, the process of data validation needs to be performed only once, so that everyone can benefit from this. Challenges are found in the rapid development of and changes in registration systems, the project financing structure, participation of hospitals and changes in legislation with respect to data usage. Currently, electronic health data are primarily registered for clinical use and a systematic interpretation for research purposes is often lacking. A related problem is the large registration burden on hospital personnel and the current focus on billable 'health products', which largely determines what is registered and how. These aspects are external factors that are mostly out of control of the project, but do complicate regular data extraction and therefore pose potential threats to the future of the data warehouse. Projects to improve source registration have already been set up in the Netherlands supported by the Federation of University medical centres, ${ }^{42}$ the Dutch Association of general hospitals and specialised institutions ${ }^{43}$ and the centre of expertise for standardisation and eHealth Nictiz, ${ }^{44}$ and, for example, in the USA by the Centers for Medicare and Medicaid Services, promoting meaningful use of certified EHR technology. ${ }^{45}$ If uniform registration will be successfully implemented in hospitals, standardised source data could be used for the data warehouse, allowing real-time data extraction. However, the analysis of imperfect data requires other solutions. For example, when patients have received multiple transfusions, we must take into account the potential for confounding in the analysis. Several analysis methods can be used, including restriction to certain cases and statistical correction using the standardisation or maximum likelihood methods. ${ }^{46}$

\section{CONCLUSION}

The DTD contributes to the optimisation of Dutch transfusion practice by enabling researchers to identify donor risk factors that affect recipients, monitor and benchmark the use of blood products both at national and international levels, and evaluate the effect of changes in the supply chain. This will contribute to optimally tailored transfusions and fewer transfusion reactions. Joint support from the blood bank, hospitals and external parties are key success factors for a future-proof and clinically relevant blood transfusion data warehouse.

\footnotetext{
Author affiliations

${ }^{1}$ Transfusion Technology Assessment Department, Sanquin Research, Amsterdam, The Netherlands

2Julius Center for Health Sciences and Primary Care, University Medical Center Utrecht, Utrecht, The Netherlands

${ }^{3}$ Department of Public and Occupational Health, EMGO Institute for Health and Care Research, VU University Medical Center, Amsterdam, The Netherlands
}

${ }^{4}$ Department of Clinical Chemistry and Haematology, University Medical Center Utrecht, Utrecht, The Netherlands

${ }^{5}$ Department of Transfusion Medicine, Sanquin Blood Bank, Amsterdam, The Netherlands

Contributors MPJ, MMWK and MCdB secured the funding of this study. BHH and PK obtained ethical and privacy approval. BHH and LRvH drafted the manuscript. MCdB, PK, MPJ, MMWK and KMKdV critically revised the manuscript. All authors approved the final version.

Funding This study was funded by Sanquin Blood Supply (PPOC-11-042). Competing interests None declared.

Provenance and peer review Not commissioned; externally peer reviewed.

Data sharing statement Our project involves building a data warehouse for use by researchers. Researchers planning a project can gain access to the data of the warehouse by completing a data request form. The project advisory board, consisting of representatives of all involved disciplines, will determine whether the request should be granted.

Open Access This is an Open Access article distributed in accordance with the Creative Commons Attribution Non Commercial (CC BY-NC 4.0) license, which permits others to distribute, remix, adapt, build upon this work noncommercially, and license their derivative works on different terms, provided the original work is properly cited and the use is non-commercial. See: http:// creativecommons.org/licenses/by-nc/4.0/

\section{REFERENCES}

1. Madge HM. On transfusion of blood. BMJ 1874;1:42.

2. Goodnough LT. Blood management: transfusion medicine comes of age. Lancet 2013;381:1791-2.

3. Goodnough LT, Levy JH, Murphy MF. Concepts of blood transfusion in adults. Lancet 2013;381:1845-54.

4. Carson JL, Carless PA, Hébert PC. Outcomes using lower vs higher hemoglobin thresholds for red blood cell transfusion. JAMA 2013;309:83-4.

5. Carson JL, Carless PA, Hébert PC. Transfusion thresholds and other strategies for guiding allogeneic red blood cell transfusion. Cochrane Database Syst Rev 2012;(4):CD002042.

6. de Almeida JP, Vincent JL, Galas FR, et al. Transfusion requirements in surgical oncology patients: a prospective, randomized controlled trial. Anesthesiology 2015;122:29-38.

7. Council of Europe: The collection, testing and use of blood and blood components in Europe. 2011 Report. 2015. https://www.edqm. eu/medias/fichiers/the_collection_testing_and_use_of_blood_and_ blood_components_in_europe_2011_report.pdf

8. Gombotz $\mathrm{H}$, Rehak $\mathrm{PH}$, Shander A, et al. The second Austrian benchmark study for blood use in elective surgery: results and practice change. Transfusion 2014;54:2646-57.

9. Jin R, Zelinka ES, McDonald J, et al. Effect of hospital culture on blood transfusion in cardiac procedures. Ann Thorac Surg 2013;95:1269-74.

10. Ejaz A, Spolverato G, Kim Y, et al. Variation in triggers and use of perioperative blood transfusion in major gastrointestinal surgery. Br J Surg 2014;101:1424-33.

11. Biggin K, Warner $P$, Prescott $R$, et al. A review of methods used in comprehensive, descriptive studies that relate red blood cell transfusion to clinical data. Transfusion 2010;50:711-18.

12. Edgren $\mathrm{G}$, Hjalgrim $\mathrm{H}$. Epidemiological considerations for the use of databases in transfusion research: a Scandinavian perspective. Curr Opin Hematol 2010;17:596-601.

13. Edgren G, Hjalgrim H, Tran TN, et al. A population-based bi-national register for monitoring long-term outcome and possible disease concordance among blood donors and recipients. Vox Sang 2006;91:316-23.

14. Edgren G, Rostgaard K, Vasan SK, et al. The new Scandinavian Donations and Transfusions database (SCANDAT2): a blood safety resource with added versatility. Transfusion 2015;55:1600-6.

15. Kleinman S, Busch MP, Murphy EL, et al. National Heart, Lung, and Blood Institute Recipient Epidemiology and Donor Evaluation Study (REDS-III). The National Heart, Lung, and Blood Institute Recipient Epidemiology and Donor Evaluation Study (REDS-III): a research program striving to improve blood donor and transfusion recipient outcomes. Transfusion 2014;54:942-55.

16. Palo R, Ali-Melkkilä T, Hanhela R, et al. Development of permanent national register of blood component use utilizing electronic hospital information systems. Vox Sang 2006;91:140-7. 
17. Chassé M, Mclntyre L, Tinmouth A, et al. Effects of blood donor characteristics in transfusion recipients: protocol of a framework to study the blood donor-recipient continuum. BMJ Open 2015;5(1): e007412.

18. Borkent-Raven BA, Janssen MP, van Der Poel CL, et al. The PROTON study: profiles of blood product transfusion recipients in the Netherlands. Vox Sang 2010;99:54-64.

19. Borkent-Raven BA, Janssen MP, van der Poel CL, et al. Survival after transfusion in the Netherlands. Vox Sang 2011;100:196-203.

20. Palo R, Ahonen J, Salo H, et al. Transfusion of red blood cells: no impact on length of hospital stay in moderately anaemic parturients. Acta Anaesthesiol Scand 2007:51:565-9.

21. Edgren $\mathrm{G}$, Hjalgrim $\mathrm{H}$, Reilly $\mathrm{M}$, et al. Risk of cancer after blood transfusion from donors with subclinical cancer: a retrospective cohort study. Lancet 2007;369:1724-30.

22. Hjalgrim H, Edgren G, Rostgaard K, et al. Cancer incidence in blood transfusion recipients. J Natl Cancer Inst 2007;99:1864-74.

23. Middelburg RA, Briët E, van der Bom JG. Mortality after transfusions, relation to donor sex. Vox Sang 2011;101:221-9.

24. Tynell E, Andersson TM, Norda R, et al. Should plasma from female donors be avoided? A population-based cohort study of plasma recipients in Sweden from 1990 through 2002. Transfusion 2010;50:1249-56.

25. Norda R, Andersson TML, Edgren G, et al. The impact of plasma preparations and their storage time on short-term posttransfusion mortality: a population-based study using the Scandinavian Donation and Transfusion database. J Trauma Acute Care Surg 2012;72:954-61.

26. Shanwell A, Andersson TM, Rostgaard K, et al. Post-transfusion mortality among recipients of ABO-compatible but non-identical plasma. Vox Sang 2009;96:316-23.

27. Edgren G, Kamper-Jørgensen M, Eloranta S, et al. Duration of red blood cell storage and survival of transfused patients (CME). Transfusion 2010:50:1185-95.

28. Lacroix J, Hébert PC, Fergusson DA, et al. Age of transfused blood in critically ill adults. $N$ Engl J Med 2015;372:1410-18.

29. Williamson LM, Devine DV. Challenges in the management of the blood supply. Lancet 2013;381:1866-75.

30. Eder A. Evidence-based selection criteria to protect blood donors. J Clin Apher 2010;25:331-7.

31. Eder AF, Dy BA, Kennedy JM, et al. The American Red Cross donor hemovigilance program: complications of blood donation reported in 2006. Transfusion 2008;48:1809-19.

32. Fan $\mathrm{W}, \mathrm{Yi} \mathrm{QL}, \mathrm{Xi}$ G, et al. The impact of increasing the upper age limit of donation on the eligible blood donor population in Canada. Transfus Med 2012;22:395-403.
33. Borkent-Raven BA, Janssen MP, Van Der Poel CL. Demographic changes and predicting blood supply and demand in the Netherlands. Transfusion 2010;50:2455-60.

34. Maki T. Optimizing blood usage through benchmarking. Transfusion 2007;47:145S-8S.

35. ISBT. ST-001-ISBT-128-Standard-Technical-Specification-v4.1.0 http://www.iccbba.org/tech-library/iccbba-documents/cellular-therapydocuments (accessed Oct 2014).

36. Geiger TL, Howard SC. Acetaminophen and diphenhydramine premedication for allergic and febrile nonhemolytic transfusion reactions: good prophylaxis or bad practice? Transfus Med Rev 2007;21:1-12.

37. Roubinian $\mathrm{NH}$, Murphy EL, Swain BE, et al. Predicting red blood cell transfusion in hospitalized patients: role of hemoglobin level, comorbidities, and illness severity. BMC Health Serv Res 2014;14:213.

38. BloodMatch study. http://www.sanquin.nl/en/research/departments/ clinical-transfusion-research/bloodmatch (accessed Jun 2016).

39. Apelseth TO, Molnar L, Arnold E, et al. Benchmarking: applications to transfusion medicine. Transfus Med Rev 2012;26:321-32.

40. Verlicchi F, Desalvo F, Zanotti G, et al. Red cell transfusion in orthopaedic surgery: a benchmark study performed combining data from different data sources. Blood Transfus 2011;9:383.

41. Heddle NM, Liu Y, Barty R, et al. Factors affecting the frequency of red blood cell outdates: an approach to establish benchmarking targets. Transfusion 2009;49:219-26.

42. Dutch Federation of University medical centers (NFU). Source registration (Dutch title: Registratie aan de bron). 2013. http://www. nfu.nl/img/pdf/13.3694_Brochure_Registratie_aan_de_bron_versie_ 4-7-13.pdf (accessed Sep 2015).

43. Dutch Association of general hospitals and specialized institutions (NVZ). Information policy: four priorities (Dutch title: Informatiebeleidsplan NVZ: vier speerpunten). https://www. nvz-ziekenhuizen.nl/onderwerpen/informatiebeleid (accessed Sep 2015).

44. Nictiz. Advice for improving the exchange of information in health care (Dutch title: Advies ter verbetering van informatie-uitwisseling in de zorg). 2015. http://www.nictiz.nl/module/360/1214/Advies_ informatie-uitwisseling_Nictiz_naar_minister_Schippers.pdf (accessed Sep 2015)

45. CMS. EHR Incentive Programs. https://www.cms.gov/ Regulations-and-Guidance/Legislation/EHRIncentivePrograms/index. $\mathrm{html}$ ?redirect=/ehrincentiveprograms (accessed Sep 2015).

46. Middelburg RA, le Cessie S, Briët E, et al. A solution to the problem of studying blood donor-related risk factors when patients have received multiple transfusions. Transfusion 2010;50:1959-66. 